40 (2) | 2011

Varia

\title{
Tradiciones alfareras del valle de Cajamarca y cuenca alta del Jequetepeque, Perú
}

Production céramique dans la vallée de Cajamarca et haut bassin du

Jequetepeque, Pérou

Ceramic productions from the Cajamarca valley and high river basin of the

Jequetepeque, Peru

\section{Isabelle Druc}

\section{(2) OpenEdition}

\section{Journals}

Edición electrónica

URL: http://journals.openedition.org/bifea/1438

DOI: $10.4000 /$ bifea. 1438

ISSN: 2076-5827

\section{Editor}

Institut Français d'Études Andines

\section{Edición impresa}

Fecha de publicación: 1 agosto 2011

Paginación: 307-331

ISSN: 0303-7495

\section{Referencia electrónica}

Isabelle Druc, «Tradiciones alfareras del valle de Cajamarca y cuenca alta del Jequetepeque, Perú », Bulletin de l'Institut français d'études andines [En línea], 40 (2) | 2011, Publicado el 01 febrero 2012, consultado el 07 noviembre 2020. URL : http://journals.openedition.org/bifea/1438 ; DOI : https:// doi.org/10.4000/bifea.1438

\section{(c) $(1) \odot$}

Les contenus du Bulletin de l'Institut français d'études andines sont mis à disposition selon les termes de la licence Creative Commons Attribution - Pas d'Utilisation Commerciale - Pas de Modification 4.0 International. 


\title{
Tradiciones alfareras del valle de Cajamarca y cuenca alta del Jequetepeque, Perú
}

\author{
Isabelle Druc*
}

\section{Resumen}

Este artículo presenta las tradiciones alfareras de dos regiones del departamento de Cajamarca: el valle de Cajamarca y la región de San Pablo en la cuenca alta del Jequetepeque. Este estudio etnoarqueológico enfoca las materias primas utilizadas, las fuentes y el proceso de producción, y ofrece un cuadro interpretativo para los datos cerámicos del sitio Formativo de Kuntur Wasi. Los resultados permiten evaluar las posibilidades y áreas de producción alrededor de Kuntur Wasi, proponiendo una posible zona de adquisición y producción hasta unos 15 kilómetros al nor/noreste del sitio y posiblemente en el área de Sangal, cerca de Kuntur Wasi.

Palabras clave: producción cerámica, etnoarqueología, alfareros andinos, Cajamarca, Perú

\section{Production céramique dans la vallée de Cajamarca et haut bassin du Jequetepeque, Pérou}

\section{Résumé}

Cet article présente des données ethnoarchéologiques sur la production céramique traditionnelle dans deux régions du département de Cajamarca, dans les Andes nord péruviennes: la vallée de 
Cajamarca et la région de San Pablo, dans le haut bassin du Jequetepeque. Cette étude se concentre sur l'aspect technologique du processus de production, sur les matières premières et les sources d'approvisionnement. Elle offre un cadre d'interprétation des données céramiques pour le site Formatif de Kuntur Wasi. Les résultats permettent d'évaluer les possibilités et aires de production autour du site, avec une possible zone d'acquisition et de production jusqu'à 15 kilomètres au nord/nord-est de Kuntur Wasi, ainsi que dans la région de Sangal, proche du site.

Mots clés : production céramique, ethnoarchéologie, potiers andins, Cajamarca, Pérou

\title{
Ceramic productions from the Cajamarca valley and high river basin of the Jequetepeque, Peru
}

\begin{abstract}
This article presents the traditional ceramic production of two regions in the department of Cajamarca: the valley of Cajamarca and the region of San Pablo in the high river basin of the Jequetepeque. This ethnoarchaeological study focuses on raw materials, catchment areas and production processes, and offers an interpretative framework for the ceramic data of the Formative site of Kuntur Wasi. The results help us evaluate the possibilities of pottery production around the archaeological site, and allow us to propose a possible production area 15 kilometers to the north/north-east of Kuntur Wasi, and possibly also close to Sangal near Kuntur Wasi.
\end{abstract}

Key words: ceramic production, ethnoarchaeology, Andean potters, Cajamarca, Peru

\section{INTRODUCCIÓN}

Este estudio de las tradiciones cerámicas de Cajamarca se impulsó al iniciar, con el Dr. Kinya Inokuchi, un proyecto de análisis de la composición de la cerámica de Kuntur Wasi, centro ceremonial del periodo Formativo en el cerro «La Copa», cerca de San Pablo, cuenca alta del Jequetepeque, departamento de Cajamarca. El objetivo del presente estudio es tener un mejor conocimiento de la producción cerámica tradicional y de los materiales utilizados, y colectar fragmentos de ollas y muestras de materias primas, para metas comparativas con el material arqueológico. Tenemos presente que más de 2000 años nos separan del mundo social y cultural que tratamos de entender. Nos brinda, sin embargo, datos importantes sobre las posibilidades de producción a nivel regional, alrededor de Kuntur Wasi.

El presente artículo contiene informaciones etnográficas, en muchos casos nuevas, que completan los datos conocidos previamente y que deben entenderse como tal. De otro modo, se presenta un modelo teórico que resume la problemática 
y la hipótesis de trabajo para los análisis cerámicos que se llevarán a cabo dentro del marco del proyecto Kuntur Wasi. El estudio de las tradiciones alfareras en la región de Cajamarca, aunque lejana de la región de San Pablo (véase fig. 1), se justifica por las similitudes estilísticas observadas entre la cerámica de los sitios de Kuntur Wasi y HuacalomaLayzón (cerca de la ciudad de Cajamarca) durante la fase Sotera en Kuntur Wasi, última fase de ocupación del sitio, al final del Formativo (Inokuchi, 2010). Por lo tanto, se piensa que es posible que Kuntur Wasi haya recibido influencia del valle de Cajamarca (Inokuchi, 1998), lo que deja abierta la posibilidad de contactos e intercambios de productos, incluyendo la cerámica hecha en este valle. Las muestras e informaciones que se han recogido en Cajamarca permitirán probar esa hipótesis, comprobando la composición mineral de la cerámica de Kuntur Wasi con la de las muestras cajamarquinas y la geología

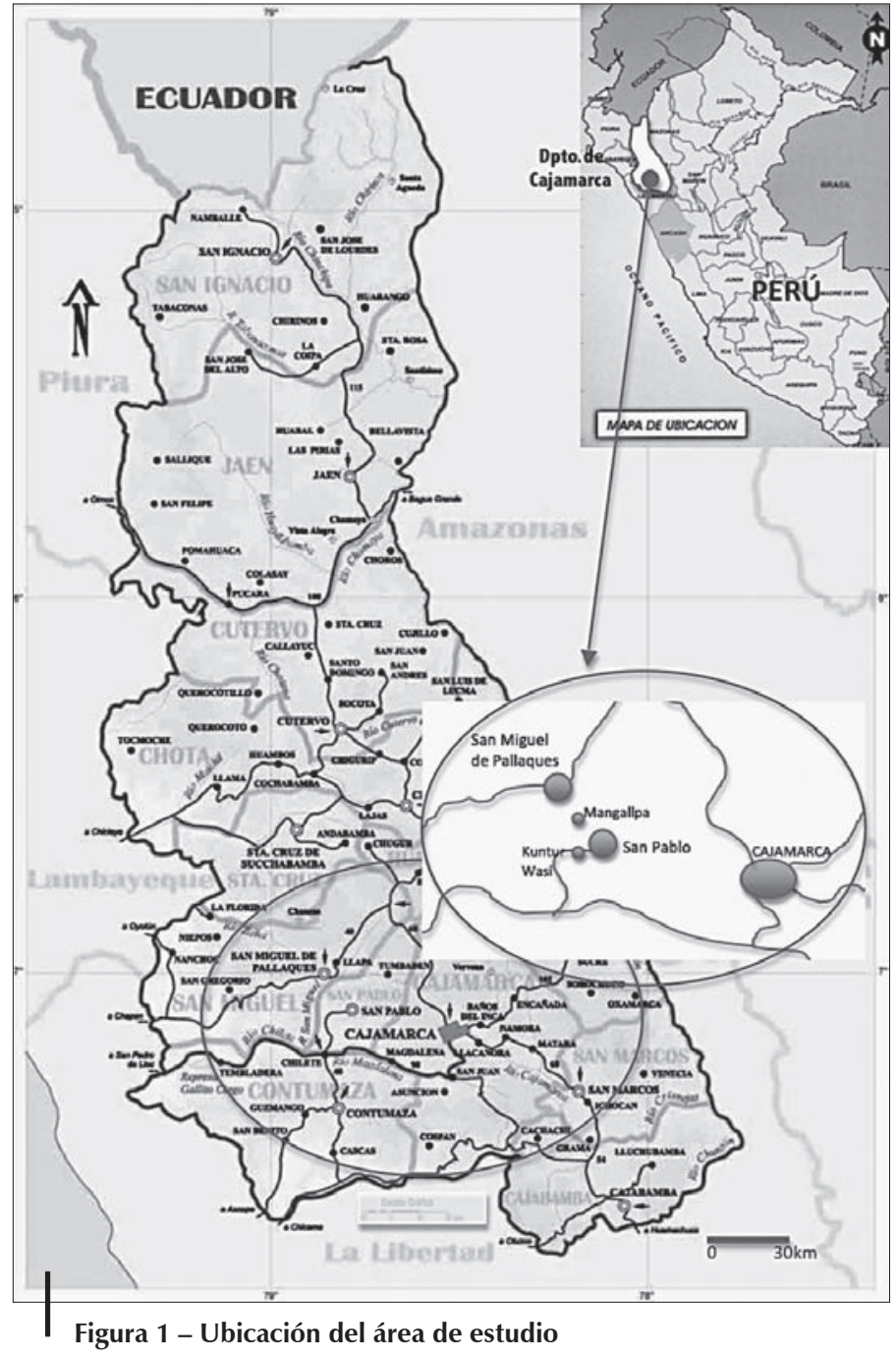

Basado en el mapa físico político del departamento de Cajamarca del lugar. Cabe notar que hoy en día se encuentra la cerámica de Cajamarca en el mercado dominical de San Pablo. También, el estudio etnográfico hecho alrededor del sitio de Kuntur Wasi, que incluye la región de San Pablo, permite darnos cuenta de las posibilidades de producción en esta región. Para nuestro objetivo, los pocos estudios anteriores hechos tanto de la región de Cajamarca como de la de San Pablo, no son suficientemente detallados, especialmente la información sobre las materias primas, los lugares con buenas arcillas y la red de distribución de los productos.

Se tratarán primero los datos obtenidos para Cajamarca, en el valle del mismo nombre, luego los de Mangallpa y San Pablo en la cuenca alta del Jequetepeque. 


\title{
1. CERÁMICA CON MOLDE Y CERÁMICA PALETEADA DE CAJAMARCA, VALLE DE CAJAMARCA
}

\begin{abstract}
A pesar de la fama de la cerámica de Cajamarca, el proceso de producción cerámica en el valle de Cajamarca no fue objeto de muchos estudios etnográficos. La cerámica está brevemente descrita e ilustrada por Rogger Ravines con el ejemplo de Mollepampa (1989a; 1989b), una comunidad localizada a 4 km al sureste del centro de la ciudad de Cajamarca que Ravines visitó en 1976 y 1985 . Un estudio de los materiales y procesos utilizados en la producción cerámica actual se ha hecho también dentro del marco del proyecto arqueológico Huacaloma-Layzón, bajo la dirección del Dr. Yuji Seki y publicado en japonés. Un resumen en español debería ser publicado proximamente (Y. Seki, comunicación personal, agosto de 2010).

Actualmente, Mollepampa se ha vuelto barrio de Cajamarca y sigue siendo un sitio de alta producción de ollas de cocina. Otro lugar de producción en Cajamarca es el sector de Cruz Blanca, a la salida de la ciudad, en la carretera que va hacia la costa. Allí se ubican varios ceramistas; estos sin embargo, se dedican más a la producción de cerámica decorativa, utilitaria y turística, aunque producen también ollas y platos para cocina.
\end{abstract}

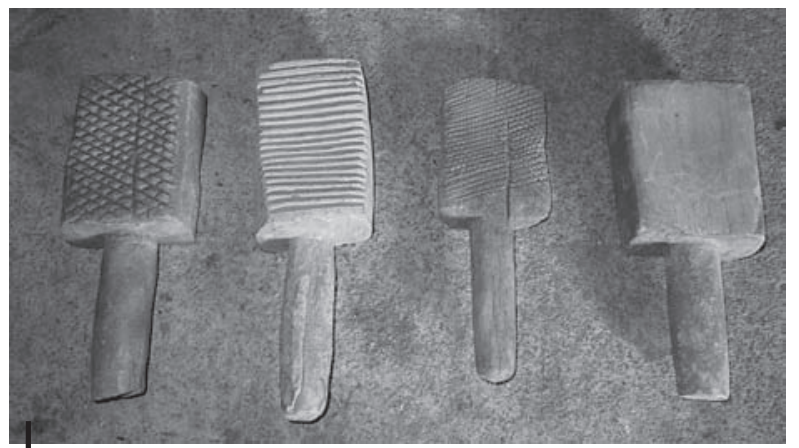

Figura 2 - Juego de paletas de Leoncio Reyes Saldaña, Mollepampa, Cajamarca

Paleta de la izquierda: $21 \mathrm{~cm}$ de largo. Las tres primeras paletas son para decorar, la cuarta paleta — sin incisionessirve para la elaboración de ollas

\section{1. Cerámica de Mollepampa}

La técnica de elaboración en Mollepampa sigue siendo el moldeado con moldes bivalvos, como está descrito por Ravines (1989b). El paleteado para elaborar piezas, que había fotografiado Ravines en 1976 (1989a) está desapareciendo1. La técnica del moldeado se ha vuelto predominante en la producción de ollas rústicas. Paletas (también llamadas palmetas o tablas) con rayas para decorar ollas y cántaros siguen siendo utilizados a menudo (fig. 2)2; pero son muy pocos los alfareros que usan paletas para elaborar las ollas; es decir, producen sin molde. Se encontró solamente un alfarero en Mollepampa que sigue con esta técnica de modo ocasional o a pedido, Leoncio Reyes Saldaña, del barrio La Tulpuna, cerca de Mollepampa. Parece que hay otro alfarero que también produce con paletas, pero esta información no está confirmada.

1 Para una revisión y discusión sobre la técnica del paleteado véase el artículo de Ramón Joffré (2008).

2 Todas las fotos han sido tomadas por el autor (agosto de 2010). 


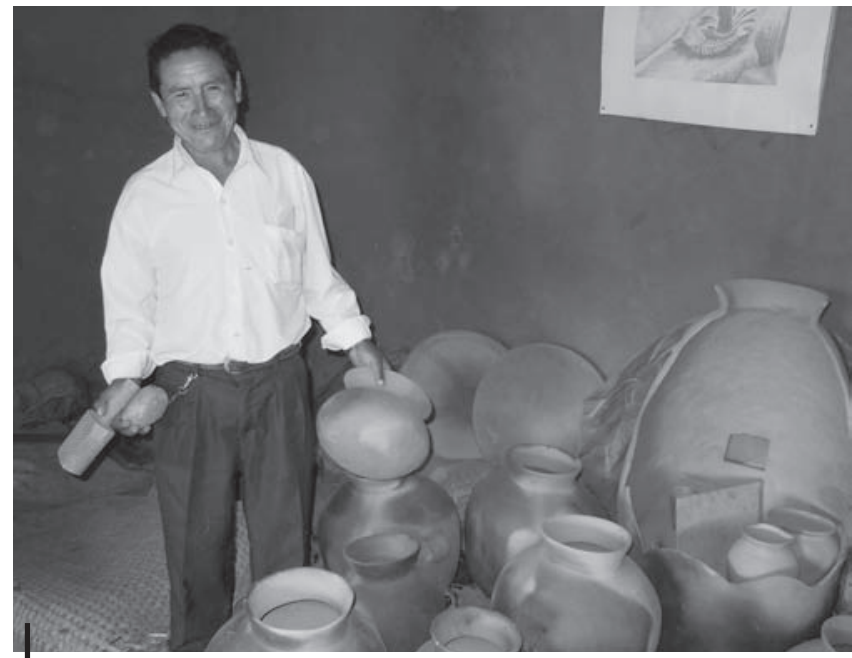

Figura 3 - Leoncio Reyes Saldaña, alfarero en Mollepampa, Cajamarca, con algunas vasijas elaboradas con la técnica del paleteado

La descripción siguiente hace referencia a Leoncio Reyes y la técnica del paleteado, luego se presentará la del moldeado. El enfoque, a lo largo de este estudio, concierne los materiales usados y la preparación de la pasta; aspectos que muchas veces no son detallados en los estudios etnográficos, pero que son importantes para estudios etnoarqueológicos, de análisis de pasta y estudios de procedencia.

\section{1. 1. Leoncio Reyes Saldaña, técnica del paleteado en Mollepampa}

Cuando se entrevistó a Leoncio Reyes (fig. 3), este regresaba del trabajo — un sector administrativo en la Universidad Nacional de Cajamarca-. Anteriormente trabajó varios años en el taller artesanal de la misma universidad que, en ese entonces, era también una escuela profesional para ceramistas. Actualmente este taller se dedica únicamente a la producción cerámica. Leoncio dice que en Aylambo mismo no hay arcilla (a pesar de que algunos olleros manifestaron que iban a buscar arcilla allí), y que han realizado varias pruebas con distintas tierras de la región. Sin embargo, varios alfareros dicen que hay arcilla en Guitarrero, cerca de Aylambo.

Leoncio aprendió de su padre, además de venir de una familia de alfareros en la que siempre se elaboraban ollas con la técnica del paleteado. Cuenta que fue invitado a varias partes de la provincia y de la costa norte para demostrar esa técnica, pero que nunca fue a producir en otra parte. Son los de Mangallpa que viajan para producir, dice, y menciona que antes ellos venían hasta Cajamarca pero que ahora ya no lo hacen.

- Materias primas: Leoncio utiliza mito (arcilla) de Shudal, un terreno a media hora a pie de su casa, cerca de la escuela de Shudal, y la arena la obtiene del Cumbe. Estos dos sitios fueron excavados también por su padre y abuelos. Los materiales se muelen, se mezclan con agua y se trabaja la pasta para llegar a la 
consistencia deseada. La mezcla para hacer ollas es de 2 latas de mito por 1 lata de arena. Para urpus y ollas más grandes se agrega ladrillo molido.

- Elaboración: Leoncio elabora sus ollas sentado en el piso trabajando sobre un cuero, con la bola de arcilla, la paleta y el mazo o chungo, piedra redonda que sirve de contrapeso. No se utiliza plato de alfarero como en la zona de Ancash (Druc, 2005). Va formando su olla, golpeando el material con la paleta y de una sola bola de barro sale una olla chiquita. Para cántaros o urpus, sienta la base en una rosca de fibra, seguidamente agrega un chorizo de pasta (o cordón), levantando la pared con la paleta. Él va girando alrededor del cántaro, más no se gira la vasija.

- La quema se hace en un horno rectangular de ladrillo, con leña en la cámara de fuego y las ollas colocadas en la cámara superior. La atmósfera es mayormente oxidante, al igual que las otras producciones para ollas en Cajamarca como para las regiones de San Pablo y de San Miguel de Pallaques.

\section{1. 2. Felicita Aquino Minchan y la técnica del molde en Mollepampa}

Felicita tiene 39 años y dirige el taller cuando su esposo, Segundo Manuel Ocas Heras, no se encuentra. Toda la familia (los padres, una hija y un hijo) ayuda en la producción, que es intensiva. El día que visité el taller, un lunes de agosto, se realizaron dos horneadas; los ayudantes empaquetaban las ollas y tapas para mandarlas en camión a Chiclayo. Los intermediarios vienen a comprar la producción y llevan las ollas a distintas partes del país. La familia de Felicita siempre elaboró ollas (Leoncio Reyes es uno de sus tíos). Felicita se acuerda del tiempo cuando se elaboraban ollas en tabla (paleteada) y con chorizo (cordones), pero dice que hace unos 20 años se cambió a los moldes en Mollepampa para aumentar la velocidad de producción.

- Materias primas: Se utiliza mito de Shudal, de una cantera ubicada a $1 \mathrm{~km}$ de la casa (fig. 4) y arena del Cumbe (tierra arenosa), en la parte llamada Layzón, a dos horas a pie de la casa. Se necesita dos días de trabajo para sacar material de Layzón: un día para sacar el material con barreta, otro para cargarlo y traerlo al taller. Los materiales se dejan secar al sol, se chancan por separado y se ciernen. El taller ahora utiliza un chancador eléctrico, lo que reduce el trabajo de preparación de las materias primas de 6 a 1 día.

La mezcla es de 6 latas de arena por 5 de mito, para hacer varias ollas. Por 3 latas de mezcla se agrega un balde de agua (cerca de un galón). Se remoja toda la noche, al día siguiente se trabaja la masa de 7 de la mañana hasta la

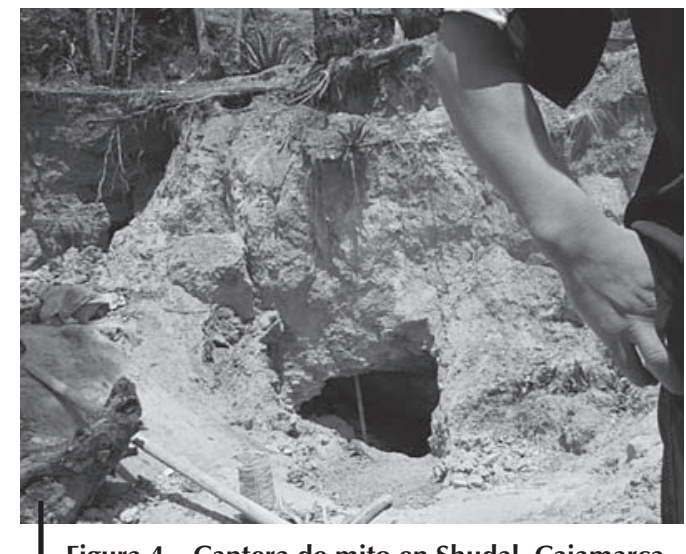

Figura 4 - Cantera de mito en Shudal, Cajamarca 
noche, posteriormente se deja cubierto hasta el día siguiente; finalmente, la masa está lista para trabajar con molde.

- Elaboración: Felicita y Segundo producen ollas rústicas con molde de yeso, con la técnica de molde bivalvo (fig. 5). El barro se agrega al molde aplastándolo con la mano; se utiliza el mismo barro para unir las dos piezas, y una vez seca la pieza, se retira el molde y se pule con agua y piedra.

- Quema: La familia tiene dos hornos de ladrillo, de dos cámaras y de planta rectangular (figs. 6 y 7), lo que permite intensificar la producción; y cuando sea necesario un uso diferenciado: un horno para piezas pequeñas, otro para piezas más grandes. Como material combustible se utiliza leña de eucalipto en la cámara inferior, colocando las ollas en la cámara superior, cubiertas con tejas. Se calienta lentamente durante una hora y luego tres horas con fuego más fuerte. Finalmente se deja enfriar un poco antes de sacar las piezas.

- Producción: Con esa técnica del molde, en un día se puede producir 100 ollas chicas, 60 ollas medianas o 12 ollas grandes. Las ollas chicas se venden a 1.50 nuevos soles, las medianas a 5 nuevos soles y las grandes a 15 nuevos soles (un dólar americano equivale a 2,72 nuevos soles, agosto de 2010). La olla mediana mide $30 \mathrm{~cm}$ de ancho, $19 \mathrm{~cm}$ de boca y $17 \mathrm{~cm}$ de alto. La familia no produce ollas decoradas con paleta. Las ollas son únicamente bruñidas.

\section{1. 3. Cerámica decorativa y moldeada en Cruz Blanca, Cajamarca}

Los talleres que están produciendo cerámica decorativa se encuentran en la carretera que sale de Cajamarca hacia la

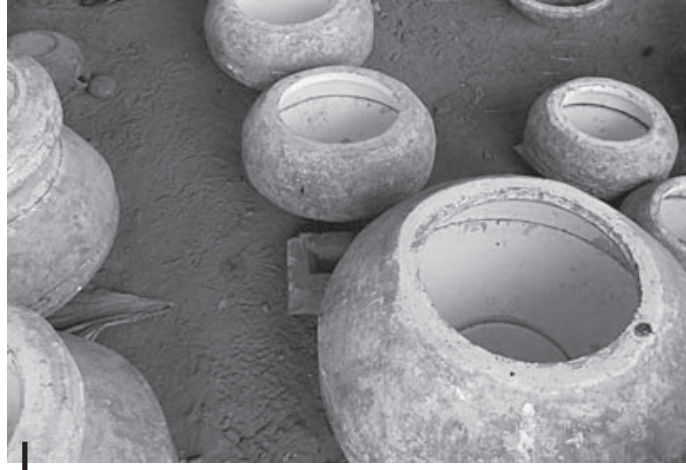

Figura 5 - Moldes utilizados por la familia Ocas Heras, Mollepampa, Cajamarca

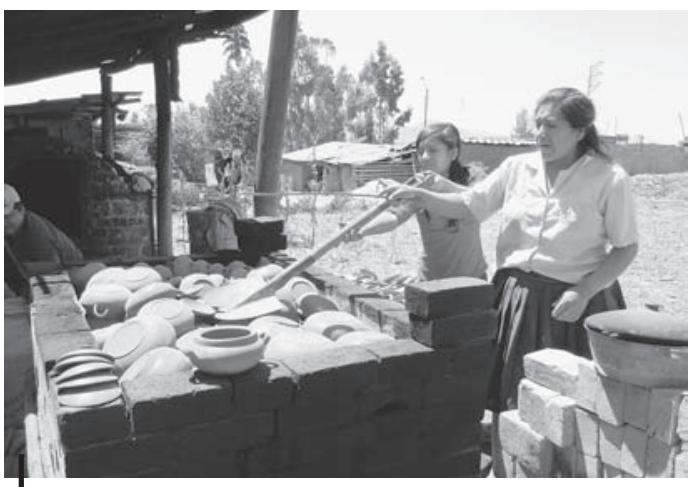

Figura 6 - Sra. Felicita Aquino Minchan y su hija sacando una horneada de ollas chicas y medianas, Mollepampa, Cajamarca

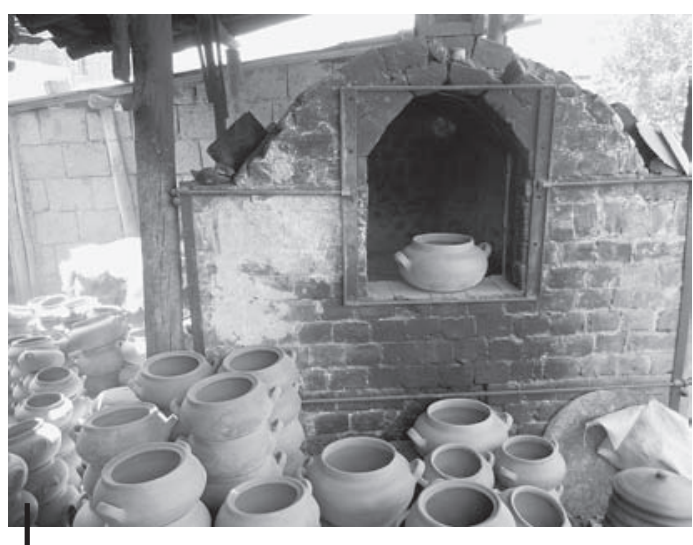

Figura 7 - Ollas de cocina y segundo horno de la familia Ocas Heras, Mollepampa, Cajamarca

Olla mediana asentada en la puerta del horno: $30 \mathrm{~cm}$ de ancho, $19 \mathrm{~cm}$ de boca y $17 \mathrm{~cm}$ de alto 


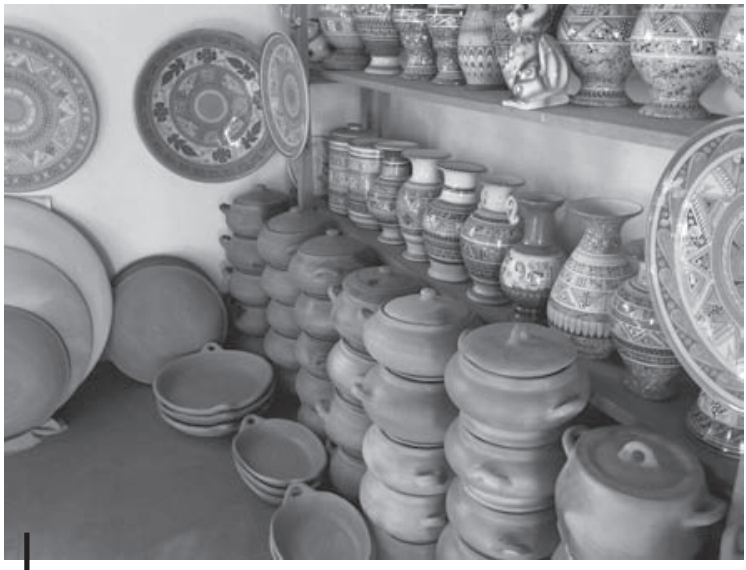

Figura 8 - Cerámica decorativa y ollas de cocina, taller Manya, Cruz Blanca, Cajamarca costa, en el sitio denominado Cruz Blanca. Estos talleres producen con moldes, mayormente cerámica fina pintada. Producen también ollas y platos de cocina (fig. 8). En Cruz Blanca visité dos talleres. Los dos utilizan los mismos materiales y técnicas. La técnica de elaboración es el moldeado con moldes bivalvos, tanto para la cerámica decorativa como para las ollas. Empezaré con la descripción de la producción de cerámica decorativa. Más adelante presentaré los materiales y el proceso de producción para la cerámica utilitaria de cocina.

- Materias primas: La composición de la mezcla para cerámica decorativa y ollas rústicas no es igual, tan solo tienen un componente en común: el mito. Para la cerámica decorativa, se necesita tres materiales: mito (tierra arcillosa), caolín (o tierra blanca) y sílice (arena). En el taller Manya, la mezcla es de 1 lata de mito, 2 latas de caolín y 1/2 de sílice. En el taller Rayitas Andinas, las proporciones son de $1 / 3$ para cada material. El mito utilizado por el taller Manya viene de Aylambo-Guitarrero a $2 \mathrm{~km}$ del taller, de un terreno grande, de 5 ó 6 hectáreas estima Manuel Manya Aquino. Manuel, de 22 años, trabaja con su papá desde hace 6 ó 7 años. Asimismo dice que hay distintos tipos de mito, que hay que seleccionar. Se excava con picos y se cobra 6 nuevos soles el saco de $100 \mathrm{~kg}$. El mito de buena calidad es escaso. Otro lugar donde se encuentra mito es Namora, a media hora en carro, por la carretera que va a San Marcos. Caolín o arcilla blanca, se encuentra en muchas partes, según Manuel Manya, y hay distintas calidades. El caolín del taller Manya viene de Gavilán, a unos 5 km de Cajamarca, de una cantera. Hay que buscar la buena veta. Uno de tipo plomo o piedra es malo. Se vende a 10 nuevos soles el saco de $100 \mathrm{~kg}$, pero como tienen que pagar peones y transporte, el saco sale finalmente a 20 nuevos soles. También hay caolín en Namora y Matara, en la ruta que conecta a la ciudad de San Marcos. El sílice utilizado por el taller Manya viene de Huayllapampa, a 2 horas y media caminando. Ahora traen el material a Cajamarca. En cuanto a la compra del material es de 8 nuevos soles el saco de $30 \mathrm{~kg}$. Parece cal o tierra blanca y se utiliza para sacar los poros del caolín al momento de preparar. También ayuda a bajar la temperatura de quema a 900 ó $950{ }^{\circ} \mathrm{C}$, según dice Manuel Manya.

Manuel comenta que todos los alfareros de Cajamarca van a estos sitios (el Cumbe, Namora) para buscar sus materiales.

- Preparación, mezcla y elaboración: La preparación de los materiales se realiza de la siguiente manera: se secan, se muelen y se ciernen con tamiz más grueso 
para el mito, y más fino (malla 95) para el caolín y la sílice. Se mezclan según las medidas al seco, y luego se agrega agua. Se amasa 3 ó 4 horas con los pies y se guarda una semana en una bolsa de plástico. Luego se utiliza la cantidad deseada, amasando con la mano. Se trabaja en molde, torno y vaciado. Para el vaciado, la masa se deja remojar 3 ó 4 meses en un balde con agua, se deja secar, se remoja y se pasa por el molde, moviendo esta pasta líquida para cubrir todo el molde. El engobe — la misma pasta pero más suave, con más aguasirve para pegar las mitades del molde. Para la cerámica decorativa, antes de la quema se aplica una pintura de piedra sobre el engobe. La pintura de piedra se saca de las mismas canteras que los materiales de base. Se mezcla con mito que permite pegar la pintura al producto3.

- Quema: La cerámica decorativa es quemada una vez solamente, en horno de ladrillo. Se quema 8 horas, lentamente las primeras 4 horas (hasta $500{ }^{\circ} \mathrm{C}$ ) para que el caolín no explote, después se agrega más leña. Se deja enfriar 10-12 horas antes de sacar las piezas.

\section{1. 4. Ollas de cocina de Cruz Blanca: molde y paleteado}

Manuel Manya aprendió de su padre. Empezó primero con ollas rústicas, luego haciendo piezas decorativas. Su familia siempre trabajó el barro. Antes, hacían piezas rústicas. Se quemaba en pampa libre, o sea en el piso o en una chacra, con leña de eucalipto debajo y paja encima.

- Materias primas: Para la cerámica de cocina se utilizan dos materiales: tierra negra y mito. La tierra del Cumbe se encuentra a 1 hora y media caminando, antes de llegar a Cumbemayo. Se trata de una cantera que tiene material volcánico debajo de la superficie. Según Manuel, hay tierra negra en dos sitios solamente: en el Cumbe y en Santa Apolonia, por Bellavista. Para grandes productos como aríbalos, se agrega media lata de chamote (teja molida) a la mezcla, para dar más fuerza a la arcilla.

- Mezcla: Las medidas son de 4 latas de tierra negra por 6 latas de mito.

- Elaboración: Las ollas se hacen con molde y con paleta para decorar (fig. 9).

- Quema: La quema se hace con horno, durante 3 a 4 horas.

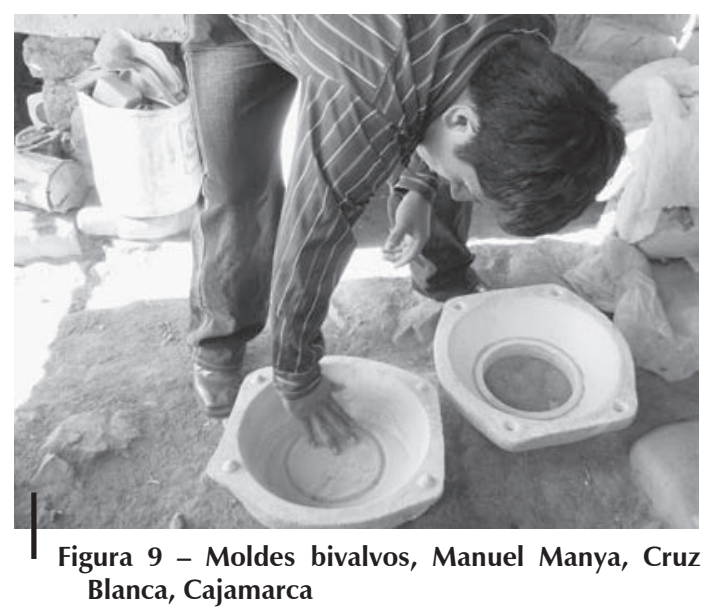

3 No se tiene mayor información en relación a esa pintura. El alfarero menciona que no es química, pero no precisó si era tipo hematita. 


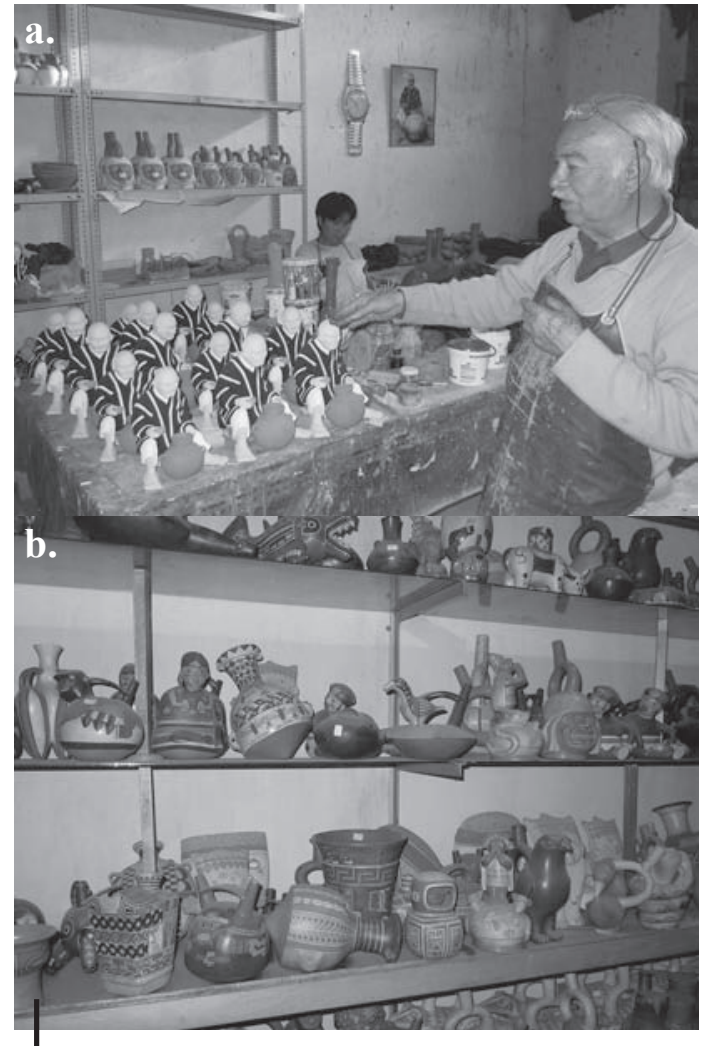

Figura 10 - Taller del Sr. Lorenzo Cabrera Abanto, cerámica decorativa (10a) e imitaciones de cerámicas arqueológicas (10b), Cajamarca

\section{1. 5. Ceramista Lorenzo Cabrera} Abanto

El señor Lorenzo Cabrera ha llevado el arte de la cerámica a un alto nivel de calidad, produciendo piezas decorativas, figuras, vasijas e imitaciones de piezas arqueológicas (fig. 10). Empezó a trabajar el barro desde el año 1968. Tiene 78 años y solamente lo ayuda un asistente. Su taller es grande, con centenares de moldes y piezas. Experimentó con varias arcillas de la región, conociendo sus calidades y características de quema. Sin embargo, produce con una sola tierra, la mejor que pudo encontrar, proveniente de un lugar conocido como «la piedra del mono»y donde ahora se ubica el Colegio San Ramón, en Cajamarca. Excavó gran cantidad de este material hace 30 años, antes de que el sitio fuera construido y el material tapado. Desde entonces ha utilizado este material para todas sus piezas.

- Materias primas: La arcilla de San Ramón es de alta temperatura y quema a $980{ }^{\circ} \mathrm{C}$. Lorenzo Cabrera menciona que la arcilla de Guitarrero y la de Namora también son de alta temperatura llegando hasta $1000{ }^{\circ} \mathrm{C}$, mientras que la de Shudal, para ollas de cocina, es de más baja temperatura, quemando entre 800 y $900{ }^{\circ} \mathrm{C}$ como máximo.

El señor Lorenzo utiliza tierra blanca tipo caolín como engobe. Proviene de la quebrada Shaullo, cerca de los Baños del Inca. Por otro lado, Lorenzo Cabrera dice que en la zona de San Marcos (aproximadamente 3 horas en bus al este de Cajamarca) y en Ichocan, hay muy buena arcilla, pero no la utiliza.

- Preparación: Lorenzo Cabrera ha implementado un sistema de pozos donde reposa su arcilla varias semanas y meses, con etapas de batidora, hasta lograr una arcilla muy fina. Se remoja 1 ó 2 meses en un primer pozo con agua, se pone a la batidora hasta que se suelta la arcilla y sus impurezas, se pone en un segundo poso de 1 semana hasta un mes, de nuevo a la batidora, luego a otro poso por 1 año.

- Elaboración: Para la elaboración utiliza la técnica del vaciado, vaciando la arcilla líquida en los moldes, logrando un producto muy fino y sin marcas de unión de los moldes. 
- Quema: Usa un horno con llama invertida y también horno eléctrico. Utiliza periódico para lograr una quema reductora a $600{ }^{\circ} \mathrm{C}$. La primera quema la hace a 900 ó $1000{ }^{\circ} \mathrm{C}$ (según el producto deseado), durante unas 8 horas. La segunda quema es a temperatura más baja y más rápida, con 3 ó 4 horas de quema. Tal control de la quema, tanto de la atmósfera como de la temperatura, es típico de ceramistas profesionales que producen cerámica decorativa y no se encuentra en las producciones de ollas y en la alfarería tradicional.

\section{1. 6. Resumen de los datos de producción cerámica para Cajamarca}

El cuadro 1 muestra un resumen de las materias primas utilizadas en los alrededores de la ciudad de Cajamarca. Vale notar que el mismo material (mito de Shudal y tierra del Cumbe) y la misma mezcla se utilizan para trabajar con molde o con paleta. En todos los casos observados, la proporción del material utilizado en la mezcla para ollas es de (1) medida de mito por (2) medidas de arena. La producción de cerámica decorativa, también con molde, utiliza otros materiales y otra mezcla. La pasta suele ser más fina y líquida para enlucir el molde. Para reforzar la pasta de grandes vasijas, se utiliza chamote. El término apunta generalmente a todo tipo de desgrasante de material hecho con barro (tiestos de cerámica, ladrillos, tejas) y molido (Rye, 1981). Este tipo de material tiene el mismo coeficiente de expansión que la cerámica (Velde \& Druc, 1999) y por lo tanto no se corre el riesgo de quiebre al momento de la quema. El nombre dado al material agregado a la arcilla difiere según los alfareros. En Cruz Blanca, Manuel lo llama tierra negra. En Mollepampa, lo llaman arena. Sin embargo, proviene del mismo sitio. Los análisis permitirán evaluar la composición de este material y clasificarlo.

Para la lista de los ceramistas entrevistados en Cajamarca, nombres y dirección, véase el anexo 1.

La figura 11 da la ubicación de los sitios mencionados para la región de Cajamarca: los centros de producción cerámica de Mollepampa y Cruz Blanca, las fuentes de materias primas y los sitios arqueológicos de Layzón y Huacaloma.

\section{PRODUCCIÓN CERÁMICA EN LAS PROVINCIAS DE SAN PABLO Y SAN MIGUEL DE PALLAQUES}

\section{1. Tradición del paleteado en Mangallpa (Cuscudén), distrito y provincia de San Pablo, Cajamarca}

Como se ha expuesto en la introducción, el objetivo de este estudio es reunir informaciones sobre la producción cerámica regional y colectar fragmentos de ollas y muestras de materias primas utilizadas en la producción alfarera tradicional para metas comparativas con material arqueológico. Por lo tanto, el enfoque del estudio hecho en Mangallpa es tecnológico. La autora visitó Mangallpa, acompañada por el Dr. Yoshio Onuki y el Lic. Raúl Cholan Cabanillas del proyecto Kuntur Wasi, en la camioneta conducida por el Sr. Luis Alcántara Huamán. 
Cuadro 1 - Procedencia de las materias primas utilizadas en Cajamarca

\begin{tabular}{|c|c|c|c|c|c|}
\hline & $\begin{array}{c}\text { Mito } \\
\text { (arcilla) }\end{array}$ & $\begin{array}{l}\text { Tierra } \\
\text { negra }\end{array}$ & $\begin{array}{l}\text { Arena } \\
\text { (sílice) }\end{array}$ & Caolín & Chamote \\
\hline $\begin{array}{l}\text { Ollas de paleta } \\
\text { (Mollepampa) }\end{array}$ & Shudal & Cumbe & & & \\
\hline $\begin{array}{l}\text { Ollas de molde } \\
\text { (Mollepampa) }\end{array}$ & Shudal & $\begin{array}{l}\text { Cumbe- } \\
\text { Layzón }\end{array}$ & & & \\
\hline $\begin{array}{l}\text { Ollas de molde } \\
\text { (Cruz Blanca) }\end{array}$ & $\begin{array}{l}\text { Aylambo- } \\
\text { Guitarrero }\end{array}$ & $\begin{array}{c}\text { Cumbe } \\
\text { Sta. Apolonia } \\
\text { (Bellavista) }\end{array}$ & & & $\begin{array}{c}\text { Tejas molidas } \\
\text { para grandes } \\
\text { vasijas }\end{array}$ \\
\hline $\begin{array}{c}\text { Piezas } \\
\text { decorativas de } \\
\text { molde } \\
\text { (Cruz Blanca) }\end{array}$ & $\begin{array}{l}\text { Aylambo- } \\
\text { Guitarrero } \\
\text { Namora }\end{array}$ & & Huayllapampa & $\begin{array}{l}\text { Gavilán } \\
\text { Namora } \\
\text { Matara }\end{array}$ & $\begin{array}{c}\text { Tejas molidas } \\
\text { para grandes } \\
\text { vasijas }\end{array}$ \\
\hline $\begin{array}{c}\text { Piezas } \\
\text { decorativas de } \\
\text { molde } \\
(\text { Sr. Lorenzo) }\end{array}$ & San Ramón & & & $\begin{array}{c}\text { Shaullo- } \\
\text { Baños Inca } \\
\text { (engobe) }\end{array}$ & \\
\hline
\end{tabular}

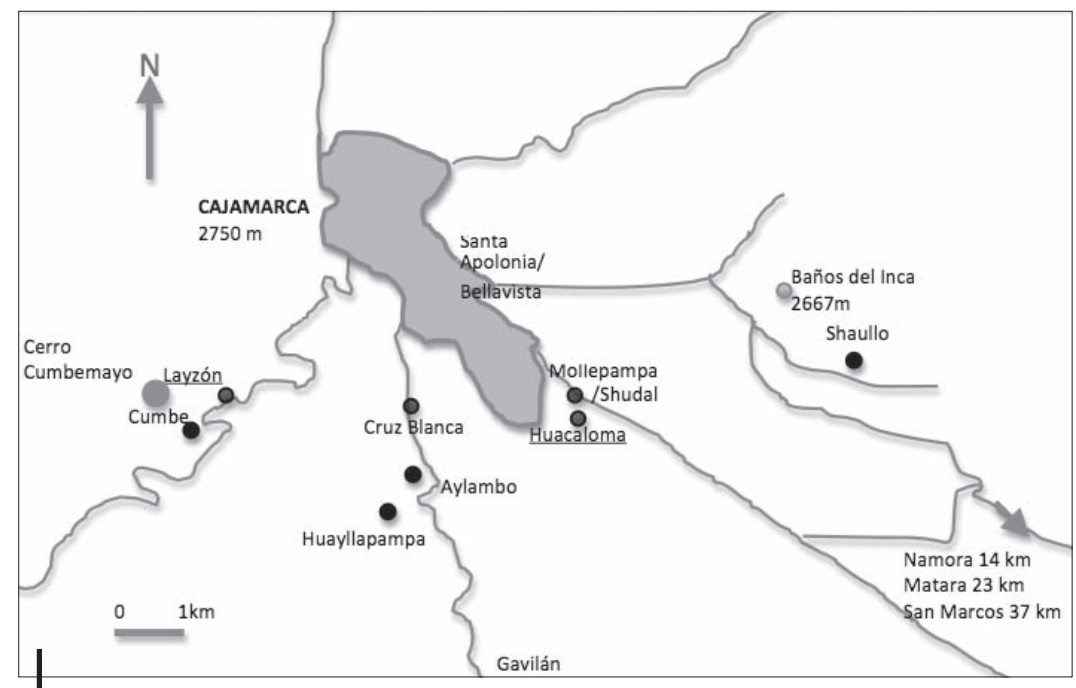

Figura 11 - Ubicación de los sitios mencionados alrededor de la ciudad de Cajamarca

Sitios de producción cerámica, de extracción de las materias primas y sitios arqueológicos de Layzón y Huacaloma (subrayados), y mayores carreteras de acceso a la ciudad 
- Ubicación: El pueblo de Mangallpa (fig. 12) se encuentra en el distrito y provincia del departamento de Cajamarca, al noreste de la ciudad misma de San Pablo y a 2200 msnm, a 40 minutos en camioneta (cuando la carretera está abierta), $7 \mathrm{~km}$ a vuelo de pájaro y 3 horas a pie para un alfarero (distancia Mangallpa-San Pablo).

- Antecedentes: El pueblo de Mangallpa o Cuscudén es conocido como pueblo alfarero por gran parte del departamento de Cajamarca. Es el único centro alfarero de la provincia de San

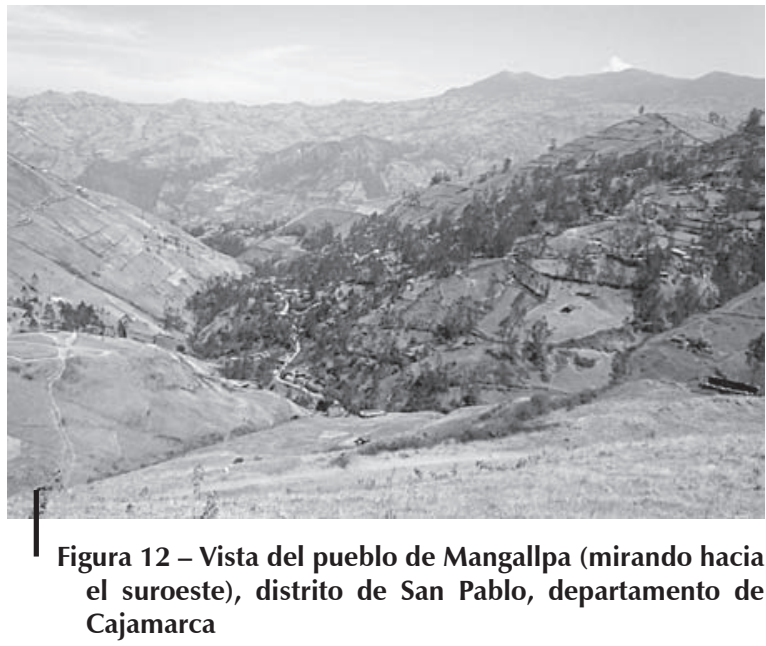
Pablo, y el más famoso de la región al oeste de Cajamarca. Varios alfareros de Mangallpa son itinerantes, saliendo a producir durante la época seca a varios sitios de la provincia, llevando con ellos sus materiales4. Otros visitan los pueblos y caseríos de la región para vender o intercambiar sus ollas con productos agrícolas o dinero. Julio Espejo Nuñez publicó en 1951 en El Comercio un pequeño artículo sobre los alfareros de Manka-Allpa, reeditado por Rogger Ravines (Espejo Nuñez, 1989). Alberto Villegas también presentó un informe acerca de la cerámica paleteada de Mangallpa en 1978, artículo reeditado por Ravines y Villiger en su compilación de 1989. Asimismo Sabogal (1977 in Ramón, ms) y Schaedel (1985) mencionan el carácter itinerante de la producción cerámica por los olleros de Mangallpa.

- Datos generales: En el año 2010 según informantes en Mangallpa, el pueblo contó con 300 familias, todas involucradas en la fabricación de ollas, aunque no todas trabajando de modo intensivo. Son los hombres los que producen y la mayor concentración de producción es en temporada seca (en invierno), generalmente de mayo-junio a noviembre.

\section{1. 1. Producción en Mangallpa}

- Materias primas: Dos tipos de materiales entran en la composición de la pasta: el mito (arcilla) y la arena (tierra arenosa). Los dos materiales se encuentran a más o menos unos 30 minutos a pie desde el pueblo caminando y se compran al dueño del terreno. Los alfareros entrevistados y gente del pueblo mencionan la existencia de tres sitios de procedencia de las materias primas: Ventanillas y Jancos Alto, donde se encuentra tanto mito como arena y Capilla Pacha para el mito. Estos sitios parecen tener varias vetas explotables y haber sido utilizados tras varias generaciones de alfareros.

4 Para una extensa discusión sobre los alfareros itinerantes, véase Ramón Joffré, ms. 
Las fuentes de Jancos Alto se encuentran al límite entre los terrenos de Cuscudén y Jancos Alto, a media hora a pie al otro lado de Ventanillas (de pueblo a pueblo es una hora a pie).

- La mezcla tiene las siguientes proporciones: 1/2 lata de mito por 1 lata de arena. Según el alfarero, en una olla a producir puede entrar un poquito más de arena, para dar fuerza a la pasta, pero por lo general, todos los alfareros siguen la misma fórmula. Para grandes ollas duplican las medidas.

- Preparación y elaboración: La preparación sigue el proceso descrito por Espejo Nuñez y Villegas. Los materiales se muelen por separado, se ciernen, se miden y se mezclan con agua hasta obtener la pasta adecuada. La olla se elabora a mano: se inicia aplastando una bola de pasta, dándole forma al fondo de la olla, utilizando una paleta y una piedra redonda como contrapeso. No se utiliza plato de alfarero. Se trabaja sentado en el piso, sobre un banco bajo o saco, la olla se mantiene entre los pies (fig. 13). La decoración exterior se aplica cuando la olla está un poco más seca con otra paleta, ésta con rayas (fig. 14). Las paletas son ligeramente trapezoidales y tienen por lo general unos $10 \mathrm{~cm}$ de largo (sin contar el mango) por 5

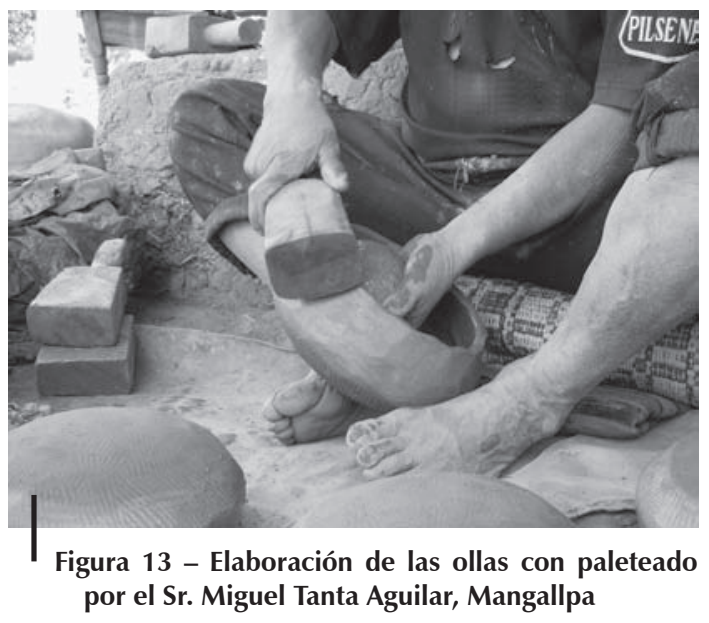
cm de espesor. Hay paletas un poco más chicas según el tamaño de la olla a producir. El señor Tanta Aguilar puede producir 40 ollas chicas en un día.

- La quema se hace al aire libre, en el piso del patio del alfarero. Se prepara un lecho de estiércol de vaca, sobre el cual se colocan las ollas. Las primeras ollas colocadas de pie en el centro, las otras de costado, alrededor y encima. Se cubre con paja, se quema durante una hora, luego se deja enfriar.

Aparte de informantes en el pueblo, los tres alfareros entrevistados fueron:

- Sr. Miguel Tanta Aguilar, y su hijo Camilito Gionbajo, barrio La Capilla, Cuscudén.

- Sr. Florencio Alejandro Alvites Valdez y su Sra. Flor Marina Tanta Sánchez, Cuscudén.

- Sr. Héctor Tanta Sánchez, Cuscudén (entrevistado en el mercado de San Pablo).

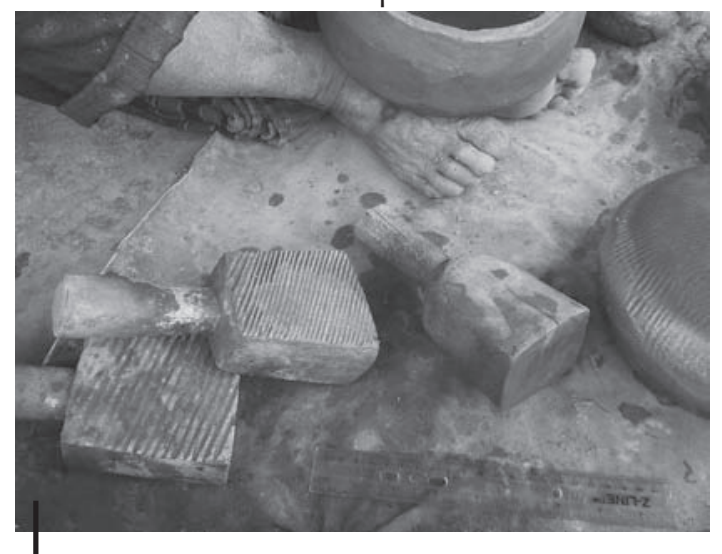

Figura 14 - Paletas para elaborar y decorar las ollas en Mangallpa

Largo de la paleta: $10 \mathrm{~cm}$, con mango: $20 \mathrm{~cm}$ 
Se recolectaron muestras de las materias primas y fragmentos de ollas para el análisis de ambas producciones. Los resultados de los análisis formarán parte de otra publicación.

\section{2. Tradición del moldeado de la provincia de San Miguel de Pallaques}

\section{2. 1. Entrevista con el alfarero Manuel Hernández Suarez}

El Sr. Hernández tiene 69 años y vive en una casa de caña y adobe en Cerro Blanco, entre Kuntur Wasi y San Pablo. Nació en Jancos Bajo, a una hora en bus al sur de San Miguel de Pallaques. Su familia hacía vasijas con moldes decorados, a la manera tradicional de la región de San Miguel de Pallaques. La familia Hernández era la única familia en Jancos Bajo produciendo cerámica. Su hermano mayor, su hermana y él aprendieron de su padre, Encarnación Hernández, con quien Manuel trabajó hasta los 24 años. Su padre murió y le dejó sus moldes. El hermano también falleció y la hermana se fue a vivir lejos. Manuel tuvo que irse y llegó con su esposa a la provincia de San Pablo. Siguió produciendo cerámica con molde con material de Jancos, en época seca, y lo que restaba del año se dedicaba a la agricultura. Hace dos años que no produce por falta de material y de recursos económicos para comprarlos.

Manuel no sabe trabajar con paleta como los de Mangallpa y dice que estos no saben hacer ollas con molde (lo que un alfarero de Mangallpa confirmó).

- Material y mezcla: Manuel comenta que la arcilla de Jancalá (véase líneas más adelante) no es tan buena como la de Jancos Alto y Mangallpa, y que allí iba con su padre a buscar material. El material se encontraba a dos horas a pie (desde Jancos Bajo) en un sitio llamado El Troje (ortografía no confirmada), al límite entre Jancos Alto y Mangallpa. Según un alfarero de Mangallpa, El Troje pertenece a la comunidad de Jancos Alto, en esa parte había tanto mito como arena. Manuel, aunque viviendo cerca de Kuntur Wasi, siguió aprovisionándose en el mismo sitio, trayendo el material a su casa. Sin embargo, el dueño del terreno ya no da acceso al material y lo ha tapado. La preparación que utiliza Manuel es de 1 lata de mito por 2 latas de arena, se agrega agua y se pisa durante 2 horas sobre un cuero de res con un pie. Con la misma preparación se produce olla chica o grande.

Manuel Hernández subraya la dificultad de preparar una buena mezcla y que trabajó varios años para aprenderla. Cuenta que su papá a veces utilizaba tiestos molidos de viejas cerámicas, moliéndolos finamente para mezclarlos con el mito, en vez de arena. Salían buenas ollas. La medida era de 1 lata de mito por 2 latas de tiesto molido. Sus tíos, en San Miguel de Pallaques, hacían lo mismo. Si no se utilizaba tiestos de cerámica, se utilizaba arena, con las mismas medidas.

- Elaboración y quema: Se hacen las ollas, jarras o platos con doble molde, unidos con un poco de agua, empujando con el chungo (piedra) y alisando con trapo. Los moldes de Manuel Hernández tienen diseños incisos, resultando 
una decoración en relieve en el producto final (fig. 15). Cabe notar que estos moldes tienen una partición vertical, lo contrario de los moldes en Cajamarca con partición horizontal. Las vasijas pueden ser pulidas con una piedra, un bruñidor. Se deja secar en la sombra, sin que le dé el viento o el sol (en el cuarto), un día hasta que se vuelva un poco blanca. Después se seca al sol dos días y luego se pone al fuego. La quema es a leña, disponiendo dos hileras de madera (perpendicularmente, dando un lecho de planta cuadrada), se colocan las ollas encima, paja, y se enciende el fuego a las 6 de la tarde. A las 6 de la mañana está listo para sacar. Se agrega paja durante la noche, pero no leña.

Manuel vende o hace trueque en los caseríos de la región: Polán, Unanca, Jallca, cargando sus ollas al hombro. Él o su familia nunca fueron a producir a otra zona. Los únicos que salen a producir — que él conozca— son los alfareros de Mangallpa.

\section{2. 2. Producción en molde en Jancalá, distrito de Llapa, provincia de San Miguel de Pallaques 5}

Según varios informantes, existe una producción cerámica en Jancalá y Llapa, caseríos a unos $3 \mathrm{~km}$ al sureste y $4 \mathrm{~km}$ al este de San Miguel de Pallaques, respectivamente. Según Manuel Hernández, en Jancalá había unas 5 ó 6 familias haciendo ollas, hombres y mujeres, hace unos 20 años. Suelen ser menos ahora. Cada familia tiene moldes con diseños y decoraciones que la distingue de otras familias (fig. 16). Según Edelmira Celes Quispe, esposa de Manuel y originaria de la región de Llapa, hay dos lugares cerca a Jancalá donde se compra material para cerámica. Un sitio es para el mito amarillo (arcilla), otro para la arena blanca. Da el nombre del Sr. Mariano Quiroz, dueño del terreno con mito, y de la familia Paucares para la arena blanca. No se pudo obtener muestras de material de Jancalá, pero el molde que mostró Manuel Hernández, hecho con este material es mucho más amarillo que los moldes hechos con material de Jancos.

Para la producción en Llapa se utilizaba mito negro y tierra blanca del Cerro de Condaje (ortografía no confirmada), según Edelmira Celes. Informaciones acerca de Llapa como sitio de producción han sido dadas también por la Sra. Paquita Arribas Plata Cabanillas, en San Pablo, pero originaria de la zona de Cochán (provincia de San Miguel de Pallaques), quien compra ollas de Jancalá a un señor de Llapa y encarga regularmente ollas y tiestos para venderlos en San Pablo (fig. 17). Llapa se encuentra al noreste de Jancalá, a una hora a pie.

5 Una visita a Jangalá, en agosto de 2011, comprobó la producción alfarera en el pueblo por 5 personas, de modo muy reducido: Cesario Medina, Apolinar Madero, Genaro Quispe Malca, y, según la profesora Maria Mónica Yeckle, el Sr. Juan y una señora (nombres no disponibles). El mito amarillo y la arena blanca se encuentran a menos de 10 minutos de las casas de los alfareros, en sus chacras o se compra al dueño del terreno. Se utiliza doble molde partidos de modo vertical. Se quema en el piso, a leña o con estiércol de vaca, con las ollas cubiertas con paja, en una hora (Genaro Quispe, comunicación personal). No salen a vender. Las ollas que la Sra. Paquita Arribas Plata Cabanillas, vende en San Pablo, vienen de Jangalá y no de Llapa, donde no hay producción ahora. El lugar de producción con molde mencionado por la Sra. Edelmira Celes Quispe, originaria de Cochán, región de Llapa, es Cachupampa a 5 km a vuelo de pájaro al sureste de Llapa. La ortografía de Jancalá se ve en el mapa geográfico del Instituto Geográfico Nacional. En el pueblo, lo escriben Jangalá. 
Tradiciones alfareras del valle de Cajamarca y cuenca alta del Jequetepeque, Perú
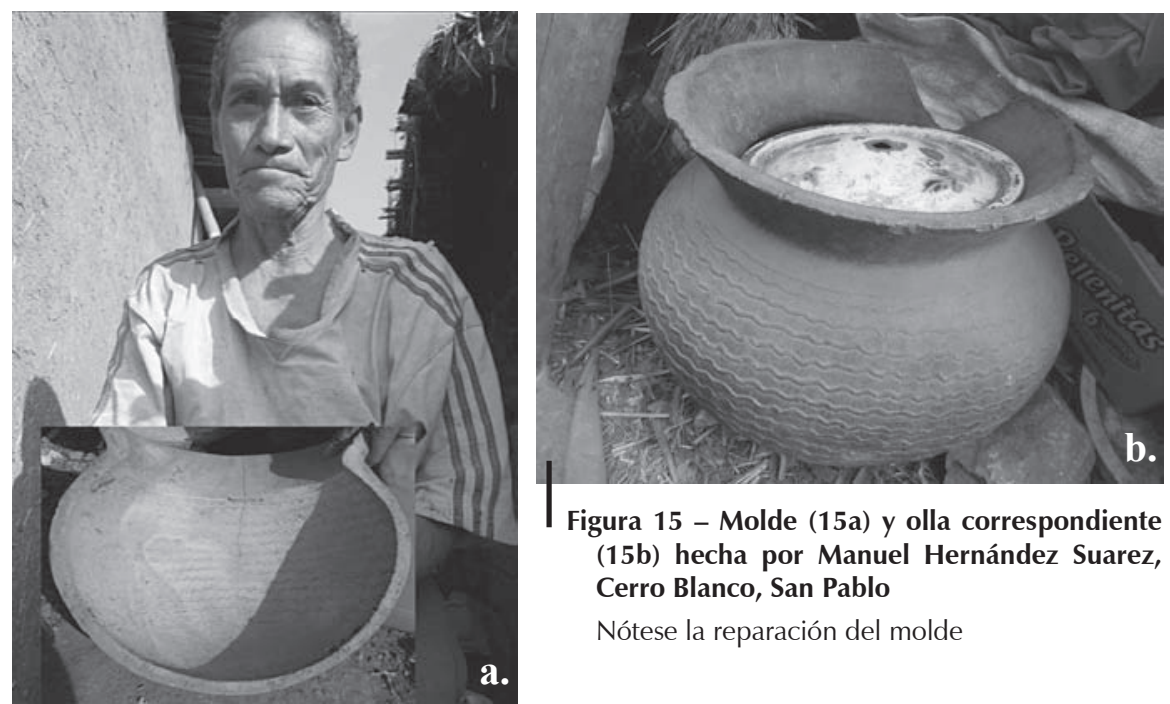

Figura 15 - Molde (15a) y olla correspondiente (15b) hecha por Manuel Hernández Suarez, Cerro Blanco, San Pablo

Nótese la reparación del molde
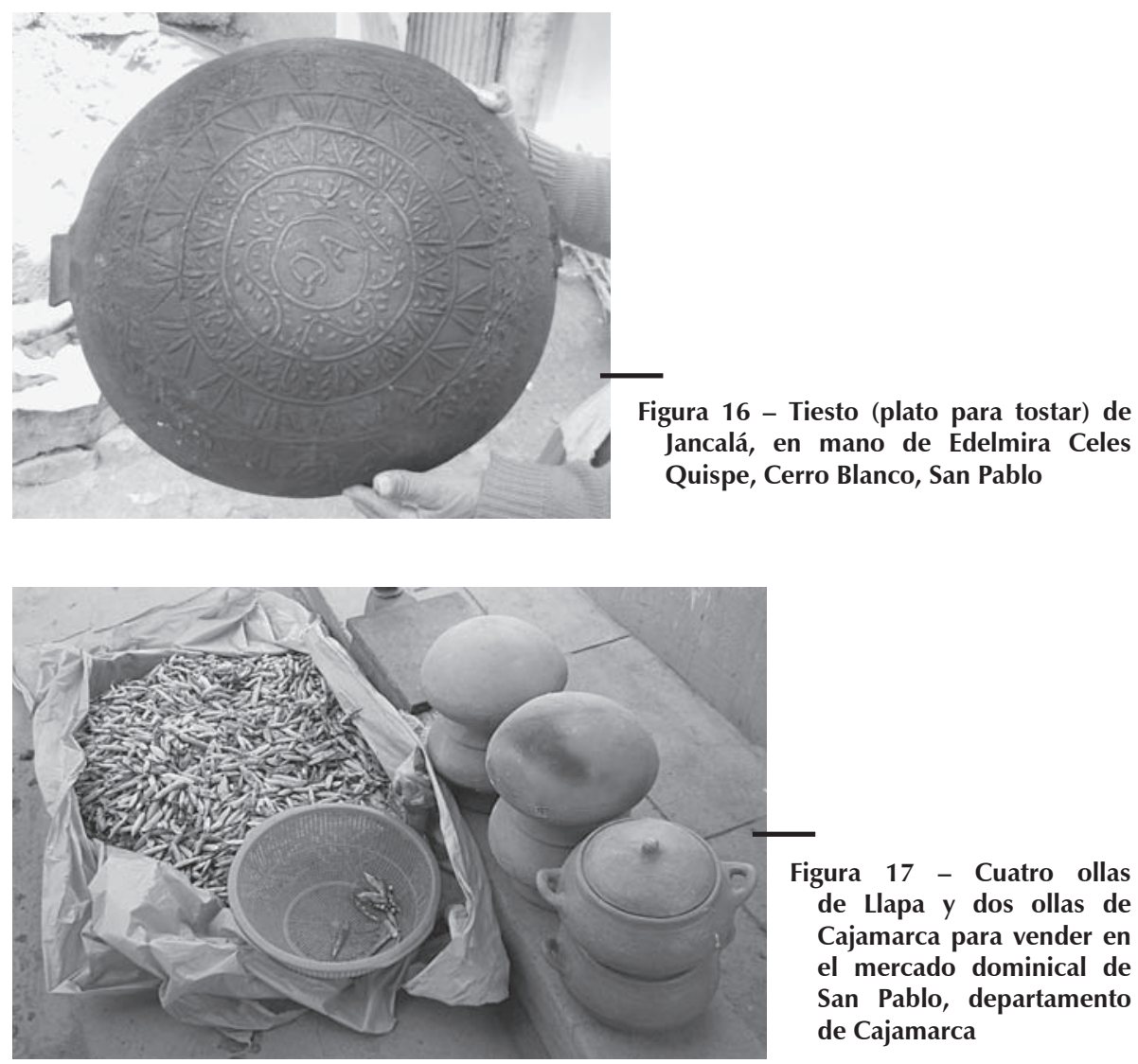

Figura 17 - Cuatro ollas de Llapa y dos ollas de Cajamarca para vender en el mercado dominical de San Pablo, departamento de Cajamarca 


\section{FUENTES DE MATERIALES EN LA REGIÓN DE KUNTUR WASI}

La prospección llevada a cabo con la ayuda del Lic. Raúl Cholan Cabanillas, arqueólogo y nativo de la provincia de San Pablo, permitió localizar la existencia de varias fuentes de mito o arcilla, en Sangal, La Laguna, San Pablo y Poquish. No significa que estas fuentes sean buenas para la producción alfarera, ni que hayan sido utilizadas en el Formativo, sino que existe un potencial para una producción local alrededor de Kuntur Wasi. Sin embargo, el mito amarillo de Sangal parece de buena calidad. Las muestras colectadas servirán de material comparativo en los análisis de cerámica.

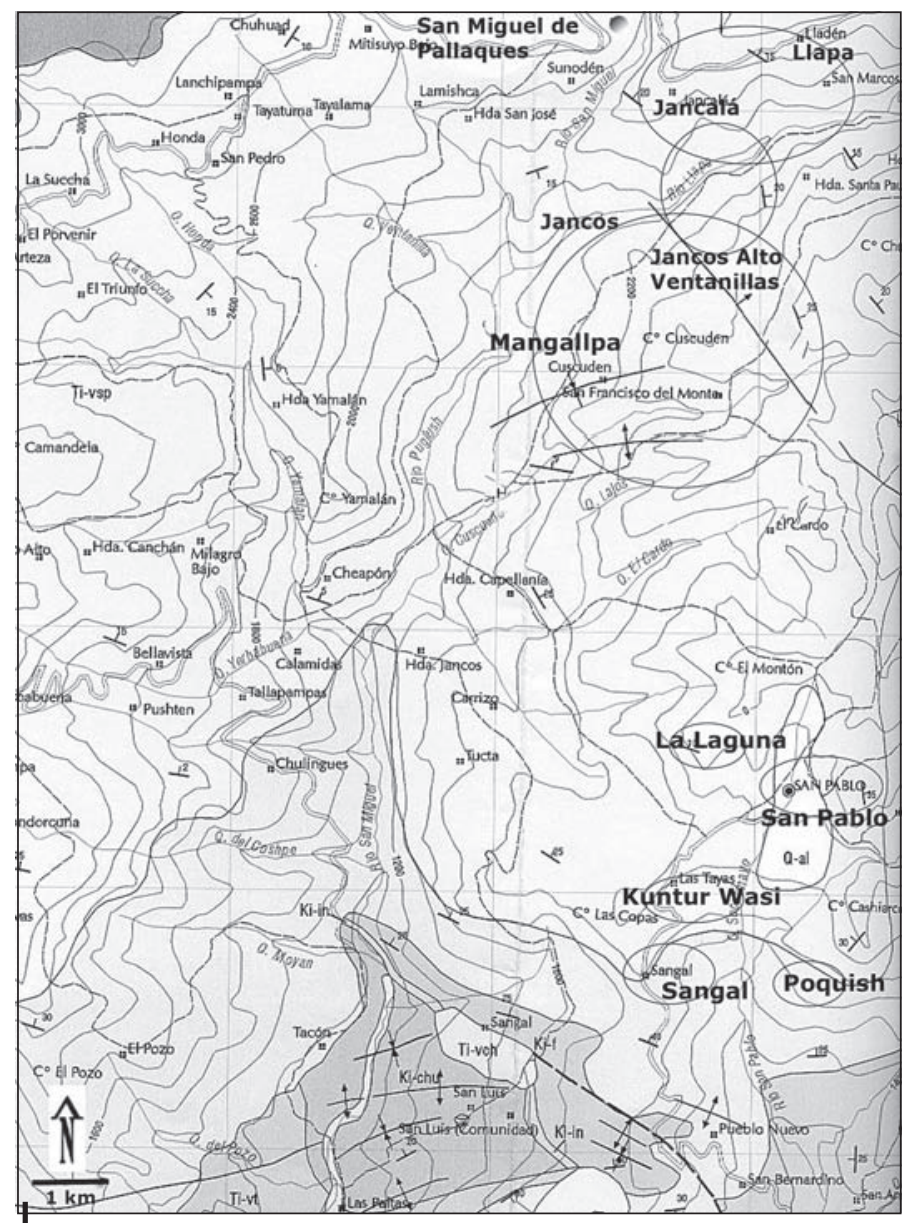

Figura 18 - Localización de los sitios de producción cerámica, de las fuentes de materias primas y de los sitios mencionados en el texto para el área de San Pablo

Basado en el mapa geológico del cuadrángulo de Cajamarca INGEMMET, Lima, 1998, hoja 15-f, 1:1000 000 
Otro material que existe en Sangal es el caolín, de muy buena calidad (Y. Seki, comunicación personal, agosto de 2010). Ese material habría podido ser utilizado para producir la cerámica con caolín tipo Cajamarca, posterior al Formativo. El periodo Cajamarca sigue la fase Sotera. En este tiempo, el sitio de Kuntur Wasi no es utilizado como centro ceremonial sino como lugar de entierro (K. Inokuchi, comunicación personal, agosto de 2010).

El mapa de la figura 18 muestra la localización de estas fuentes y de los sitios de producción mencionados para la región de San Pablo-San Miguel de Pallaques. El cuadro 2 presenta un resumen de los datos sobre la alfarería en la provincia de San Pablo.

La presencia actual de alfareros en el pueblo de San Miguel de Pallaques no está comprobada. El Sr. Hernández, originario de Jancos, menciona que sus tíos viviendo en San Miguel producían hace varios años, pero es muy probable que la mayoría de los alfareros se encuentre más en los alrededores del pueblo, hacia Jancalá y Llapa.

\section{Cuadro 2 - Cuadro recapitulado de los datos sobre la alfarería en la provincia de San Pablo}

En todos los casos dados, la proporción del material utilizado en la mezcla es de (1) medida de mito por (2) medidas de arena o de chamote

\begin{tabular}{|c|c|c|c|}
\hline $\begin{array}{l}\text { Sitios de } \\
\text { producción }\end{array}$ & $\begin{array}{c}\text { Mito } \\
\text { (arcilla) }\end{array}$ & $\begin{array}{l}\text { Arena } \\
\text { (sílice) }\end{array}$ & $\begin{array}{c}\text { Chamote (en vez de } \\
\text { arena) }\end{array}$ \\
\hline $\begin{array}{l}\text { Mangallpa } \\
\text { (paleteado) }\end{array}$ & $\begin{array}{l}\text { Ventanillas, Jancos Alto } \\
1 / 2 \text { hora a pie }\end{array}$ & $\begin{array}{c}\text { Ventanillas, Jancos Alto, } \\
\text { Capilla Pacha } \\
1 / 2 \text { hora a pie }\end{array}$ & No \\
\hline $\begin{array}{c}\text { Cerro Blanco (molde) } \\
\text { (alfarero originario de } \\
\text { Jancos) }\end{array}$ & $\begin{array}{c}\text { Jancos Alto /Mangallpa } \\
3 \text { ó } 4 \text { horas a pie }\end{array}$ & $\begin{array}{c}\text { Jancos Alto /Mangallpa } \\
3 \text { o } 4 \text { horas a pie }\end{array}$ & No \\
\hline $\begin{array}{l}\text { Jancos Bajo (molde) } \\
\text { (ya no hay alfareros) }\end{array}$ & $\begin{array}{c}\text { Jancos Alto /Mangallpa } \\
2 \text { horas a pie }\end{array}$ & $\begin{array}{c}\text { Jancos Alto /Mangallpa } \\
2 \text { horas a pie }\end{array}$ & Tiestos de cerámica \\
\hline Jancalá (molde) & $\begin{array}{c}\text { Jancalá (cerca, distancia } \\
\text { por confirmar) }\end{array}$ & $\begin{array}{c}\text { Jancalá (cerca, distancia } \\
\text { por confirmar) }\end{array}$ & Tiestos de cerámica \\
\hline Llapa (molde) & $\begin{array}{l}\text { Cro Condaje (por } \\
\text { confirmar) }\end{array}$ & $\begin{array}{l}\text { Cro Condaje (por } \\
\text { confirmar) }\end{array}$ & Sin información \\
\hline $\begin{array}{c}\text { San Miguel de } \\
\text { Pallaques (molde) }\end{array}$ & $\begin{array}{l}\text { Jancalá } \\
1 / 2 \text { hora a pie }\end{array}$ & $\begin{array}{l}\text { Jancalá } \\
1 / 2 \text { hora a pie }\end{array}$ & Tiestos de cerámica \\
\hline \multicolumn{4}{|c|}{ Materia prima } \\
\hline Sangal & \multicolumn{3}{|c|}{ Mito amarillo, en un arroyo de la quebrada, al este de Sangal } \\
\hline San Pablo & \multicolumn{3}{|c|}{ Mito amarillo, barrio La Ermita. Sitio ahora tapado por el tanque de agua } \\
\hline La Laguna & \multicolumn{3}{|c|}{ Arcilla negra en lentes mezclada con tierra, lado izquierdo de la laguna } \\
\hline Poquish & \multicolumn{3}{|c|}{$\begin{array}{l}\text { Mito de varios colores, en la desembocadura de una quebrada } \\
\text { (por confirmar) }\end{array}$} \\
\hline
\end{tabular}




\section{DISCUSIÓN Y CONCLUSIÓN}

Es interesante notar que los alfareros siguen utilizando las mismas canteras y los mismos materiales generación tras generación. Manuel Hernández, aunque le resultaba difícil y lejos debido al hecho de haberse mudado, seguía buscando material en Jancos Alto, un viaje de más de 3 horas a pie. Manuel no conoce $-y$ no busca - otra arcilla o fuentes. En varias ocasiones, se ha notado la falta o el no deseo de experimentar o tomar riesgos con un nuevo material (véase Arnold, 1985; Druc, 2005), aunque no se pueda generalizar. Existen ceramistas que, al contrario, exploran nuevos materiales y formas, y salen adelante (el caso del Sr. Lorenzo Cabrera es un ejemplo).

\section{1. Continuidad de producción y tradición}

Para la arqueología y en particular la cuestión de producción y procedencia de la cerámica, la continuidad en el uso de las fuentes y técnicas es importante. Sugiere que buenas fuentes de material son explotadas por alfareros, aunque deben venir de lejos, se utiliza lo que uno conoce (tanto material como técnica) lo que asegura una continuidad de la tradición a lo largo de los años. Dos técnicas pueden coexistir en un mismo valle (Jancos-Jancalá con molde vs. Mangallpa con paleteado) o en un mismo barrio o taller (Mollepampa y Cruz Blanca), el mismo material (mito y arena de Mangallpa) puede ser utilizado para producir con molde o solo con la técnica del paleteado.

Estas observaciones corroboran lo que se ha observado en otras partes de Perú y del mundo (vease por ejemplo: Arnold, 1993; Chávez, 1992; DeBoer \& Lathrap, 1979; Gallay \& Ceuninck, 2001; Gosselain, 2002; Kramer, 1997; Sinopoli, 1999; Vincentelli, 2004).

\section{2. Cálculo del rayo (radius) de adquisición y de producción}

Antes de seguir más adelante en esta discusión, se reflexiona sobre el concepto de distancia. En la zona andina, uno debe tener en cuenta la topografía accidentada de quebradas y montañas — que dictan el camino y la distribución de los asentamientos - y la circulación de los productos. Hablar en kilómetros como se ve en un mapa no tiene sentido. La distancia entre San Pablo y Mangallpa, por ejemplo es de $7 \mathrm{~km}$ a vuelo de pájaro, pero un alfarero necesita 3 horas a pie para venir a vender sus ollas al mercado dominical de San Pablo, porque se debe bajar y subir cerros. Esta medida pedestre es buena pero no puede trasladarse a un mapa. Por lo tanto, se sugiere usar la medida común de correlación entre tiempo y kilómetros de $5 \mathrm{~km}$ por hora. Así, el rayo de $15 \mathrm{~km}$ propuesto más adelante refleja una distancia real y el tiempo recogido tomando en cuenta la topografía local. 


\section{3. Potencial regional}

Para el caso de la cerámica de Kuntur Wasi, este primer estudio explorador de las posibilidades de producción en la región, basándose en lo que se puede observar hoy en día, sugiere que existen fuentes de buena arcilla y temperante a 3 horas a pie del sitio (caseríos de Jancos Alto y Mangallpa), se puede traer este material a otra región, Sangal, La Conga o Kuntur Wasi mismo, como se hace todavía por los alfareros de Mangallpa que recorren toda la región hasta la costa (véase Espejo Nuñez, 1989; Villegas, 1989; Ramón, ms). Hay arcilla alrededor del sitio, aunque no se sabe si está bastante buena para la producción.

Por lo tanto, se puede postular un área de adquisición de materiales dentro de un rayo de $15 \mathrm{~km}$ alrededor del sitio de Kuntur Wasi y la presencia de centros de producción alrededor del área con materias primas. Basándose en los datos para la región, los centros de producción que abastecían Kuntur Wasi con cerámica debían encontrarse a media hora o menos de las materias primas, o sea a unos $10 \mathrm{~km}$ como máximo de las fuentes. Este modelo se aplica para la producción de cerámica común, doméstica, y presentando una frecuencia alta en el sitio, como en el caso de la cerámica de la fase Copa de Kuntur Wasi. Tal cerámica, producida dentro de un rayo de $15 \mathrm{~km}$ alrededor del sitio, podría ser denominada como local, lo que incluye a la zona de Mangallpa (fig. 18). Coincide con el criterio de abundancia que estipula que la mayor parte de la cerámica encontrada en un sitio suele ser producida localmente (Harbottle, 1982: 16-17).

\section{4. Variación y cambios}

El sitio arqueológico de Kuntur Wasi presenta varias secuencias arquitectónicas y cerámicas, identificadas como fases de desarrollo. Se cuenta con las fases Idolo (950-800 a. C.), Kuntur Wasi (800-550 a. C.), Copa (550-250 a. C.) y Sotera (250-50 a. C.) (Inokuchi, 2010). Ciertos cambios sugieren la llegada de nuevos elementos o grupos humanos o una influencia estilística foránea al principio de la segunda fase - fase Kuntur Wasi- posiblemente con grupos o influencia de la costa o región Cupisnique. También se observa cambios importantes de estilos cerámicos en las dos últimas fases, Sotera I y II, con paralelos estilísticos y aportes provenientes del valle de Cajamarca, en particular del sitio de Layzón (Inokuchi, 1998; 2010; Kato, 1994; Onuki et al., 1995). Se puede pensar que al inicio de estas fases parte de la producción cerámica es no local, hecha con material y con un estilo de la región Cupisnique para el principio de la fase Kuntur Wasi y de la región de Cajamarca para la cerámica de la fase Sotera (Inokuchi, 1998). También es posible que los nuevos ocupantes contaran entre ellos a artesanos y alfareros, que llevaban al principio sus materiales y luego han ido adaptándose a las arcillas locales y al contacto de los alfareros locales. Eso no impide seguir produciendo con un estilo costeño o cajamarquino con materiales locales. Los análisis de composición de pasta que son previstos para el material de Kuntur Wasi 
ayudarán a lograr un mejor entendimiento del desarrollo de la producción alfarera en Kuntur Wasi, y del carácter local o foráneo de los distintos estilos presentes.

\section{5. Producción en cifras}

Finalmente, según los datos de excavación, en las fases Copa 1 y 2, después de la fase Kuntur Wasi 2, se observa un incremento importante del porcentaje de cerámica (Inokuchi, 1998), sugiriendo una producción más intensiva, y una población más grande. Si extrapolamos los datos de Mangallpa con una producción semanal de unas 100 ollas por familia en estación seca (40 ollas chicas en un día, produciendo por 2 ó 3 días, dejando secar, con quema y mercado el resto de la semana) pensando que 200 alfareros producen en el pueblo (son 300 familias que trabajan el barro, pero no necesariamente todas al mismo tiempo), es una producción semanal de 20000 ollas para este centro alfarero. Una temporada de producción de 2 meses (mediados de junio a mediados de agosto) lleva el total a 160000 ollas por año. Cabe notar que en agosto-septiembre un $30 \%$ de los alfareros de Mangallpa viajan a producir a otras partes, llevando con ellos sacos de material (estimación de Héctor Tanta Sánchez, alfarero en Mangallpa, agosto de 2010).

Preguntando a familias de la región, de distintos niveles económicos, la cantidad de ollas para cocinar que posee cada familia es de 7 a 10 (familias de 6 a 9 personas por lo general), y de 1 a 2 tiestos (platos para tostar) por familia. La vida de una olla de cocina sería de 2 años o más, según el uso. Así, un solo centro alfarero de Mangallpa puede proveer a 20000 familias con cerámica (promedio de 8 ollas por familia).

No podemos llevar mucho más lejos este tipo de conjetura sin conocer la población residente alrededor de Kuntur Wasi durante la fase Copa y en los caseríos alrededor, ni el promedio de ollas por familia en tiempos más antiguos. La variedad de vasijas utilizadas era también más alta. Sin embargo, este cálculo permite pensar que un solo centro alfarero del tamaño de Mangallpa habría podido abastecer de cerámica a un centro como Kuntur Wasi.

La localización de los pueblos alfareros y de las fuentes de buenos materiales para la producción cerámica en la zona entre San Miguel de Pallaques y San Pablo también brinda otra información importante. Se observa que las fuentes explotadas se concentran entre Jancalá, Jancos y Mangallpa, con varios sitios de producción alrededor. Abarca una zona de unos $30 \mathrm{~km}^{2}$, entre 2000 y 2400 msnm, al este de la carretera que va de San Pablo a San Miguel, y a unas 3 ó 5 horas a pie al noreste de Kuntur Wasi. No se reporta la presencia de pueblos donde producen cerámica o de fuentes, al oeste o al sur de esta zona. 


\section{Agradecimientos}

Quiero agradecer al Dr. Kinya Inokuchi del proyecto Kuntur Wasi por su apoyo e interés, sin los cuales este estudio no se habría realizado. El proyecto Kuntur Wasi brindó también un apoyo logístico importante, facilitando movilidad y trabajo. Del mismo modo quiero agradecer al Lic. Raúl Cholán Cabanillas, arqueólogo en Kuntur Wasi, quien me acompañó en giras de prospección, aprovechando su gran conocimiento de la región. De igual manera, agradezco al Sr. Juan Cabanillas por un memorable viaje hacia una quebrada en busca de mito. Agradezco también al Dr. Yoshio Onuki y la Sra. Teresa Onuki por su amabilidad y generosidad y a las demás personas que me proveyeron información, en particular a los alfareros que entrevisté. Finalmente mi mayor gratitud a la Universidad de Saitama, Japón, que otorgó los fondos para este estudio.

\section{Anexo 1}

\section{Ceramistas entrevistados en Cajamarca}

\section{Cerámica decorativa utilitaria «Manya»}

- Modesto Manya Cachi (padre pero en Lima)

- Manuel Manya Aquino (22 años)

- Rosa Elvira Aquino

Av. Independencia 1296, Cajamarca

\section{Cerámica Rayita de los Andes}

- (Baltazar) Cruz Blanca, Cajamarca

\section{1. Ollas con molde}

- Familia Segundo Manuel Ocas Heras

- Felicita Aquina Minchan (39 años)

Av. Alfonso Ugarte 2008, Mollepampa - Cajamarca

2. 2. Ollas paleteadas

- Leoncio Reyes Saldaña

Av. Alfonso Ugarte 1432, Barrio La Tupuna - Cajamarca

\section{3. Artandina}

- Lorenzo H. Cabrera Abanto, ceramista

Jr. José Olaya 660, Cajamarca 


\section{Referencias citadas}

ARNOLD, D. E., 1985 - Ceramic theory and cultural process, 268 pp.; Cambridge: Cambridge University Press.

ARNOLD, D. E., 1993 - Ecology and ceramic production in an Andean community, 278 pp.; New York: Cambridge University Press.

CHÁVEZ, K. L. M., 1992 - The organization of production and distribution of traditional pottery in South Highland Peru. In: Ceramic production and distribution (G. J. Bey III \& C. A. Pool, eds.): 49-92; Boulder: Westview Press.

DE BOER, W. R. \& LATHRAP, D. W., 1979 - The making and breaking of Shipibo-Conibo ceramics. In: Ethnoarchaeology: implications of ethnography for archaeology (C. Kramer, ed.): 102-138; New York: Columbia University Press.

DRUC, I., 2005 - Producción cerámica y etnoarqueología en Conchucos, Ancash, Perú, 100 pp.; Lima: Runa.

ESPEJO NUÑEZ, J., 1989 - Los alfareros de Manka-allpa. In: La cerámica tradicional del Perú (R. Ravines \& F. Villiger, eds.): 91- 92; Lima: Los Pinos.

GALLAY, A. \& CEUNINCK, G., 2001 -Étude ethnoarchéologique des traditions céramiques du pays Dogon, 117 pp.; Genève: Département d'Anthropologie et d'Écologie de I'Université de Genève.

GOSSElAIN, O., 2002 - Poteries du Cameroun méridional, 254 pp.; París: Éditions du Centre National de la Recherche Scientifique (CNRS). Collection de Recherches Archéologiques (CRA) Monographies 26.

HARBOTTLE, G., 1982 - Chemical characterization in archaeology. In: Context for prehistoric Exchange (J. E. Ericson \& T. K. Earle, eds.): 13-51; New York: Academic Press.

INOKUCHI, K., 1998 - La cerámica de Kuntur Wasi y el problema Chavín. Boletín de Arqueología PUCP, 2: 161-180.

INOKUCHI, K., 2010 - La arquitectura de Kuntur Wasi: secuencia constructiva y cronología de un centro ceremonial del Periodo Formativo. Boletín de Arqueología PUCP, 12: 219-248.

KATO, Y., 1994 - Resultados de las excavaciones en Kuntur Wasi, Cajamarca. In: El mundo ceremonial andino (L. Millones \& Y. Onuki, eds.): 199-224; Lima: Horizonte.

KRAMER, C.,1997 - Pottery in Rajasthan: ethnoarchaeology in two Indian cities, 264 pp.; Washington: Smithsonian Institution Press

ONUKI, Y., KATO, Y. \& INOKUCHI, K., 1995 - La primera parte: Las excavaciones en Kuntur Wasi, la primera etapa, 1988-1990. In: Kuntur Wasi y Cerro Blanco (Y. Onuki, ed.): 1-126; Tokyo: Hokusen-Sha.

RAMÓN JOFFRÉ, G., 2008 - Producción alfarera en Piura (Perú). Estilo técnico y diacronía. Bulletin de I'Institut Français de Études Andines, 37 (3): 477-509.

RAMÓN JOFFRÉ, G., ms. - Los alfareros golondrinos, 102 pp. Manuscrito inédito.

RAVINES, R., 1989a - Proceso alfarero en Mollepampa Cajamarca, 1976. In: La cerámica tradicional del Perú (R. Ravines \& F. Villiger, eds.): 95-98; Lima: Los Pinos.

RAVINES, R., 1989b - Proceso alfarero en Mollepampa Cajamarca, 1985. In: La cerámica tradicional del Perú (R. Ravines \& F. Villiger, eds.): 99-104; Lima: Los Pinos.

RYE, O., 1981 - Pottery Technology. Principles and reconstruction, 150 pp.; Washington: Taraxacum.

SABOGAL, J., 1977 - Alfareros golondrinos del valle de Jequetepeque. III Congreso Nacional del Folklore-Victor Navarro del Águila, Lima [conferencia inédita]. 
Tradiciones alfareras del valle de Cajamarca y cuenca alta del Jequetepeque, Perú

SCHAEDEL, R., 1985 - Coastal-Highland Interrelationships and ethnic groups in Northern Peru (500 B.C.-A.D. 1980). In: Andean ecology and civilization: an interdisciplinary perspective on Andean ecological complementarity (S. Masuda, I. Shimada \& C. Morris, eds.): 443-474; Tokyo: University of Tokyo Press.

SINOPOLI, C. M., 1999 - Levels of complexity: Ceramic variability at Vijayanagara. In: Pottery and People (J. M. Skibo \& G. M. Feinman, eds.): 115-136; Salt Lake City: The University of Utah Press.

VELDE, B. \& DRUC, I., 1999 - Archaeological ceramic materials, 299 pp.; Berlín: Springer Verlag.

VILLEGAS, A., 1989 - Cerámica paleteada de Mangallpa. In: La cerámica tradicional del Perú (R. Ravines \& F. Villiger, eds.): 93-94; Lima: Los Pinos.

VINCENTELLI, M., 2004 -Women Potters. Transforming Traditions, 240 pp.; New Brunswick \& New Jersey: Rutgers University Press. 